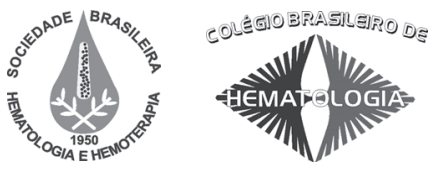

\title{
Quantificação das citocinas séricas Th1/Th2 por citometria de fluxo no linfoma de Hodgkin clássico
}

\section{Measurement of Th1/Th2 serum cytokines by flow cytometry in classical Hodgkin lymphoma}

\author{
Adriana K. Mitelman \\ Valeria Buccheri ${ }^{2}$ \\ Luis F. Pracchia ${ }^{2}$ \\ Claudia V. Rubens ${ }^{3}$ \\ Santa Poppe ${ }^{4}$ \\ Alexandra M. M. P. Cavalcante \\ Sandra M. Monteiro ${ }^{4}$
}

\begin{abstract}
O linfoma de Hodgkin clássico (LHC) é uma neoplasia com distúrbio na produção de citocinas. Estudos demonstram que o padrão anormal das citocinas no linfonodo acometido pela lesão contribui não somente com a proliferação das células malignas H-RS, como também com o característico infiltrado hiper-reativo que compõe o tecido no LHC. Esta disfunção pode ser observada tanto no quadro clínico dos pacientes, como nas características histopatológicas: sintomas B, deficiência na resposta imune celular, bandas de colágeno e eosinofilia. As concentrações séricas das citocinas Th1 (IL-2, TNF, INF- $\gamma$ ) e Th2 (IL-4, IL-5, IL-10) foram estudadas em 45 pacientes com LHC, ao diagnóstico, e em 34 doadores saudáveis, por citometria de fluxo (CBA - cytometric beads array). Houve aumento das concentrações das citocinas TNF ( $p<0,01), I N F-\gamma(p<0,01), I L-4$ $(p=0,01), I L-5(p<0,01)$ e IL-10 $(p<0,01)$ dos pacientes quando comparados com o grupo controle. Não foi evidenciada diferença em relação a IL-2. Ao correlacionarmos as concentrações das citocinas Th1/Th2 com as variáveis clínico-laboratoriais dos pacientes, observou-se que niveis elevados da IL-10 (Th2) estão correlacionados com as variáveis que implicam em pior prognóstico: estádios III/IV $(p=0,01)$, presença de sintomas $B(p=0,04)$, hemoglobina $<10,5 \mathrm{~g} / \mathrm{dL}(p=0,01)$, linfócitos $\leq 600 \mathrm{~mm}^{3}(p=0,01)$ $e$, de acordo com o IPI, os pacientes de alto risco $(p=0,01)$. Por outro lado, niveis séricos elevados da IL-2 (Th1) foram encontrados em estádio I/II, quando comparados com III/ IV $(p=0,03)$, o que indica que a IL-2 diminui com a progressão da doença. Os resultados sugerem que a IL-10 possa estar regulando negativamente a resposta imune citotóxica (Th1) pela inibição da IL-2. Há uma possível associação entre progressão da doença e níveis elevados da IL-10. Esse estudo evidenciou que a utilização do CBA é factivel na detecção das citocinas, e que as alterações encontradas podem estar envolvidas na biologia do LHC. Rev. Bras. Hematol. Hemoter. 2009;31(4):260-266.
\end{abstract}

Palavras-chave: Linfoma de Hodgkin clássico; citocinas; citometria de fluxo; CBA; células Th1; células Th2.

\section{Introdução}

O linfoma de Hodgkin clássico (LHC) é uma neoplasia linfoide com características próprias que o distingue do linfoma de Hodgkin predominância linfocitária nodular
(LHPLN) e dos linfomas não Hodgkin (NLH). As células malignas no LHC, células multinucleadas Reed-Sternberg e as células mononucleares de Hodgkin (H-RS) constituem o menor componente do tumor ( $1 \%-2 \%)$, enquanto a população celular predominante é composta por células reativas ou inflama-

\footnotetext{
${ }^{1}$ Bióloga.

Correspondência: Adriana Korn Mitelman

Rua Emilio de Menezes, 27, $4^{\circ}$ andar - Higienópolis

01231-020 - São Paulo-SP - Brasil

E-mail:amitelman@uol.com.br

Doi: 10.1590/S1516-84842009005000060
}

${ }^{2}$ Professor colaborador do FMUSP - Faculdade de Medicina da Universidade de São Paulo - São Paulo-SP

${ }^{3}$ Biomédica do Laboratório de Imunopatologia e Citometria de Fluxo do Hospital Albert Einstein - São Paulo-SP.

${ }^{4}$ Bióloga do Laboratório de Imunologia e Alergia LIM-60 na FMUSP - Faculdade de Medicina da Universidade de São Paulo - São Paulo-SP. ${ }_{5}^{5}$ Bióloga do Laboratório de Citometria de Fluxo do Hospital Albert Einstein - São Paulo-SP.

Faculdade de Medicina da Universidade de São Paulo (FMUSP) - São Paulo-SP. 
tórias, como linfócitos, células plasmáticas, histiócitos, neutrófilos, eosinófilos e células estromais (98\%). ${ }^{1}$

Nos últimos anos, vários estudos têm sugerido que o LHC é uma neoplasia que se apresenta com alterações na produção de citocinas. Esses estudos demonstraram que o padrão anormal de expressão das citocinas no linfonodo acometido pela doença contribui para a proliferação das células H-RS e também é responsável pelo infiltrado hiper-reativo que compõe o tecido no LHC. ${ }^{2,3}$ Além disso, essa disfunção também pode ser notada, em uma proporção de pacientes, pela presença de sintomas $\mathrm{B}$ (febre $\geq 38^{\circ} \mathrm{C}$, sudorese noturna e perda de peso $>$ de $10 \%$ do peso corporal nos últimos seis meses), nos cortes histológicos por meio das bandas de colágeno (fibrose) e eosinofilia e pela deficiência da resposta imune celular. ${ }^{2,4,5}$

A imunidade adaptativa apresenta dois tipos de resposta: (1) resposta imune humoral, pela estimulação dos linfócitos B a produzirem anticorpos; e (2) resposta imune celular, onde os linfócitos T CD8+ com ação citotóxica e os macrófagos são ativados. Os linfócitos CD4+ participam de ambas as respostas pelo reconhecimento do antígeno e subsequente diferenciação em suas subpopulações efetoras Th1 ou Th2., ${ }^{4,6}$ As células Th1 facilitam a resposta imune celular ou citotóxica pela produção das citocinas IL-2, INF $\gamma \mathrm{e}$ TNF, enquanto as células Th2 secretam, principalmente, a IL4, IL-5 e IL-10, que auxiliam os linfócitos B a produzirem anticorpos, facilitando a resposta imune humoral. ${ }^{6}$

Nesse estudo avaliamos a expressão das citocinas Th1/Th2 séricas em pacientes com LHC, ao diagnóstico, por citometria de fluxo (CBA - cytometric beads array), visando um melhor entendimento da disfunção da resposta imune, sua correlação com as variáveis clínico-laboratoriais dos pacientes e se há uma possível relação com prognóstico.

\section{Casuística e Método}

Foram incluídos neste estudo 45 pacientes consecutivos, diagnosticados com LHC no Serviço de Hematologia do Hospital das Clínicas da Faculdade de Medicina da Universidade de São Paulo (HC-FMUSP), no período de maio de 2005 a outubro de 2006. Os critérios de inclusão utilizados foram: diagnóstico histológico de LHC de acordo com a Classificação da Organização Mundial de Saúde, idade acima de 12 anos, soronegatividade para HIV e Hepatite C, ausência de outra neoplasia e de tratamento oncológico prévio. O grupo controle foi constituído por 34 indivíduos normais, doadores voluntários do Banco de Sangue do Hospital Samaritano de São Paulo. O estudo foi aprovado pelo Comitê de Ética Médica do HC-FMUSP e todos os pacientes e doadores voluntários assinaram o Termo de Consentimento Livre e Esclarecido.

As amostras de sangue periférico foram colhidas para análise imunofenotípica por citometria de fluxo (CMF) ao diagnóstico, e alíquotas de soro e plasma foram separadas e congeladas a $-20^{\circ} \mathrm{C}$ para posterior detecção das citocinas séricas por citometria de fluxo. O ensaio da detecção de citocinas foi realizado no laboratório de Imunologia e Alergia (LIM-60) do HC-FMUSP.

A análise imunofenotípica foi realizada nas amostras obtidas dos pacientes e do grupo controle em tubos contendo anticoagulante EDTA. Todas as amostras foram avaliadas pelo método de tripla marcação com uma combinação de diferentes fluorocromos: isotílcianato de fluoresceína (FITC), ficoeritrina (PE) e ficoeritrina-cianina 5 (PE/CY5). Nas amostras dos 45 pacientes e dos 34 indivíduos normais, a imunofenotipagem foi realizada utilizando-se um painel de anticorpos monoclonais (AcMo) capaz de identificar os antígenos de superfície celular da linhagem linfoide B (CD19), linhagem linfoide T (CD3, CD4, CD8), células NK (CD16, CD56, CD57), molécula de adesão de granulócitos (CD15) e células ativadas (CD25, CD28, CD38). O CD3 (antígeno linfocitário T) foi adicionado em todos os tubos e utilizado como marcador comum. O ajuste das fluorescências, bem como a aquisição e análise dos dados foram realizados no citômetro de fluxo FACScalibur (BD Biosciences - Immunocytometry Systems, San Diego, CA, USA) utilizando-se o programa FACScomp (BD) e CellQuest (BD) respectivamente.

O Kit CBA (BD) (cytometric beads array) foi usado nesse estudo para a quantificação das citocinas IL-2, INF $\gamma$ e TNF (Th1) e IL-4, IL-5, IL-10 (Th2) em uma mesma amostra. Seis populações de beads com distintas intensidades de fluorescência são conjugadas com um anticorpo de captura específico para cada citocina, misturadas para formar o CBA e lidas no canal FL3 do citômetro de fluxo FACScalibur (BD). As populações de beads foram visualizadas de acordo com as suas respectivas intensidades de fluorescência: da menos brilhante para a mais brilhante. No CBA, as beads de captura das citocinas são misturadas com o anticorpo de detecção conjugado com o fluorocromo PE, e depois incubadas com as amostras para formar o ensaio "em sanduíche". Os tubos para aquisição foram preparados com: $50 \mu \mathrm{L}$ de amostra, $50 \mu \mathrm{L}$ da mistura de beads e $50 \mu \mathrm{L}$ do reagente de detecção Th1/Th2 PE (Human Th1/Th2 PE Detection Reagent/1 vial, $4 \mathrm{~mL}$ ). O mesmo procedimento foi realizado para a obtenção da curva-padrão. Os tubos foram homogenizados e incubados por três horas, em temperatura ambiente, no escuro. Os resultados foram gerados em gráficos e tabelas utilizando-se o software CellQuest (BD).

Mediante revisão de prontuários clínicos, foram obtidos dados sobre as seguintes variáveis prognósticas: idade, sexo, estádio, presença de doença bulky, presença de sintomas B, concentração de hemoglobina sérica, leucometria, linfometria, nível de albumina sérica e velocidade de hemossedimentação (VHS). Também foi calculado o Índice Prognóstico Internacional (IPI) para cada paciente, conforme previamente descrito. $^{7}$ 
A análise univariada dos níveis séricos de citocinas e da porcentagem de subtipos linfocitários entre pacientes e controles e entre as variáveis prognósticas foi efetuada através do teste não paramétrico de Mann-Whitney. Todos os testes foram bicaudais com nível de significância definido em 5\%. Para a análise dos dados foi utilizado o software SPSS 10.0.

\section{Resultados}

Os 45 pacientes analisados apresentaram idade mediana de 32 anos (13 a 82 anos); 25 (56\%) eram do sexo masculino. As características clínicas e laboratoriais dos pacientes estão descritas na Tabela 1. O grupo controle dos 34 indivíduos normais apresentou idade mediana de 35 anos (20 a 61 anos).

A comparação do fenótipo dos linfócitos de sangue periférico, entre pacientes e o grupo controle, mostrou uma diminuição na mediana da porcentagem de linfócitos $T$ $\mathrm{CD} 3+\mathrm{CD} 4+$, estatisticamente significante nos pacientes $(\mathrm{p}=0,02)$. Também a análise imunofenotípica demonstrou um aumento na mediana da porcentagem da população de linfócitos $\mathrm{CD} 3+\mathrm{CD} 8+$ nos pacientes $(\mathrm{p}=0,02)$.

Com relação à população de linfócitos $\mathrm{B}(\mathrm{CD} 19+)$ foi observada uma diminuição na mediana da sua porcentagem nos pacientes quando comparada com o grupo controle $(\mathrm{p}<0,01)$. Por outro lado, observou-se um aumento na mediana da porcentagem dos linfócitos natural killer (NK) maduros (CD57+CD3-), estatisticamente significante, nos pacientes $(\mathrm{p}=0,02)$.

A comparação das citocinas séricas entre pacientes, ao diagnóstico, e grupo controle mostrou maior concentração das citocinas TNF $(p<0,01)$, INF- $\gamma(p<0,01)$, IL-4 ( $p=0,01)$, IL-5 ( $<<0,01)$ e IL-10 $(p<0,01)$ no grupo de pacientes. Porém, não se observou diferença com relação à concentração sérica da IL-2 entre os dois grupos.

Os resultados, em mediana, da concentração das citocinas (Th1/Th2) no sangue periférico, correlacionados com as variáveis prognósticas do LHC, estão descritos nas Tabelas 2 e 3: citocinas Th1 (TNF, INF- $\gamma$, IL-2) e citocinas Th2 (IL-4, IL-5, IL-10).

Nas citocinas Th1, a concentração de TNF e o INF- $\gamma$ não mostraram valores estatisticamente significantes quando correlacionados com as variáveis prognósticas nos pacientes. Por outro lado, a IL-2 se mostrou aumentada no grupo de pacientes com valores de albumina $<4,0 \mathrm{~g} / \mathrm{dL}(\mathrm{p}=0,01)$ e nos pacientes com estádio precoce I/II da doença $(\mathrm{p}=0,03)$ (Tabela 2)

Nas citocinas Th2, a concentração da citocina IL-4 estava elevada no grupo de pacientes com linfopenia (linfócitos $\left.\leq 600 \mathrm{~mm}^{3}\right)(\mathrm{p}=0,02)$. A IL-5 não apresentou alteração estatisticamente significante em relação a nenhum fator prognóstico estudado. Porém, a IL-10 estava elevada, com valores estatisticamente significantes, no grupo de pacientes
Tabela 1. Características demográficas, clínicas e laboratoriais dos pacientes.

\begin{tabular}{|c|c|}
\hline Variável & $n=45(\%)$ \\
\hline $\begin{array}{l}\text { Idade } \\
\quad<45 \text { anos } \\
\quad \geq 45 \text { anos }\end{array}$ & $\begin{array}{l}31(69) \\
14(31)\end{array}$ \\
\hline $\begin{array}{l}\text { Sexo } \\
\text { Masculino } \\
\text { Feminino }\end{array}$ & $\begin{array}{l}20(56) \\
20(44)\end{array}$ \\
\hline $\begin{array}{l}\text { Subtipo Histológico - LHC } \\
\text { Rico m linfócitos } \\
\text { Esclerose nodular } \\
\text { Celularidade Mista } \\
\text { Depleção Linfocitária } \\
\text { Não classificável }\end{array}$ & $\begin{array}{c}3(7) \\
32(71) \\
3(7) \\
1(2) \\
6(13)\end{array}$ \\
\hline $\begin{array}{l}\text { Fenótipo }{ }^{1} \\
\text { CD30 + } \\
\text { CD15 + } \\
\text { EBV (LMP-1) + }\end{array}$ & $\begin{array}{l}44(98) \\
38(84) \\
9(32)\end{array}$ \\
\hline $\begin{array}{l}\text { Está dio clínico } \\
\text { I/II } \\
\text { III/IV }\end{array}$ & $\begin{array}{l}15(33) \\
30(67)\end{array}$ \\
\hline $\begin{array}{l}\text { Sintomas B } \\
\text { Presentes } \\
\text { Ausentes }\end{array}$ & $\begin{array}{l}20(57) \\
15(43)\end{array}$ \\
\hline $\begin{array}{l}\text { Doença bulky } \\
\text { Ausente } \\
\text { Presente }\end{array}$ & $\begin{array}{l}18(40) \\
27(60)\end{array}$ \\
\hline $\begin{array}{l}\text { Hemoglobina } \\
\quad \geq 10,5 \mathrm{~g} / \mathrm{dL} \\
\quad<10,5 \mathrm{~g} / \mathrm{dL}\end{array}$ & $\begin{array}{l}14(31) \\
31(69)\end{array}$ \\
\hline $\begin{array}{l}\text { Leucócitos } \\
\quad<15000 \mathrm{~mm}^{3} \\
\geq 15000 \mathrm{~mm}^{3}\end{array}$ & $\begin{array}{l}35(78) \\
10(22)\end{array}$ \\
\hline $\begin{array}{l}\text { Linfócitos } \\
\quad>600 \mathrm{~mm}^{3} \\
\leq 600 \mathrm{~mm}^{3}\end{array}$ & $\begin{array}{c}40(89) \\
5(11)\end{array}$ \\
\hline $\begin{array}{l}\text { Albumina } \\
\quad \geq 4,0 \mathrm{~g} / \mathrm{dL} \\
<4,0 \mathrm{~g} / \mathrm{dL}\end{array}$ & $\begin{array}{l}10(22) \\
35(78)\end{array}$ \\
\hline $\begin{array}{l}\text { Velocidade de hemossedimenta } \\
\text { Até } 50 \mathrm{~mm} / \mathrm{h} \\
\text { Acima } 50 \mathrm{~mm} / \mathrm{h}\end{array}$ & $\begin{array}{l}17(40) \\
26(60)\end{array}$ \\
\hline $\begin{array}{l}\text { Índice Prognóstico Internaciona } \\
\text { Baixo Risco } \\
\text { Alto Risco }\end{array}$ & $\begin{array}{l}22(49) \\
23(51)\end{array}$ \\
\hline
\end{tabular}

'Imuno-histoquímica para EBV não realizada em 17 pacientes ${ }^{2}$ Dado ignorado em 2 pacientes

classificados nos estádios III/IV ( $\mathrm{p}=0,01)$, presença de sintomas $\mathrm{B}(\mathrm{p}=0,04)$, hemoglobina $<10,5 \mathrm{~g} / \mathrm{dL}(\mathrm{p}=0,01)$, linfócitos $\leq 600 \mathrm{~mm}^{3}(\mathrm{p}=0,01)$ e, de acordo com o IPI, pacientes de alto $\operatorname{risco}(\mathrm{p}=0,01)$.

\section{Discussão}

A imunofenotipagem de sangue periférico em pacientes com LHC, ao diagnóstico, mostrou alterações nas populações linfocitárias que caracterizam um perfil imune reacional. 
Tabela 2. Correlação entre citocinas séricas Th-1 (TNF, INF- $\gamma$, IL-2) e variáveis prognósticas

\begin{tabular}{|c|c|c|c|c|c|c|}
\hline Variável Prognóstica & $\begin{array}{c}\text { TNF pg/mL } \\
\text { mediana } \\
\text { (variação) }\end{array}$ & $p$ & $\begin{array}{c}\text { INF- } \gamma \text { pg/mL } \\
\text { mediana (variação) }\end{array}$ & $\mathrm{p}$ & $\begin{array}{l}\mathrm{IL}-2 \mathrm{pg} / \mathrm{mL} \\
\text { mediana } \\
\text { (variação) }\end{array}$ & $\mathrm{p}$ \\
\hline \multicolumn{7}{|l|}{ Idade } \\
\hline $\begin{array}{l}<45 \text { anos } \\
\geq 45 \text { anos }\end{array}$ & $\begin{array}{l}2,5(0-7,1) \\
2,0(0-8,4)\end{array}$ & 0,09 & $\begin{array}{l}2,1(0-38,3) \\
2,6(0-41,1)\end{array}$ & 0,46 & $\begin{array}{l}0,5(0-3,3) \\
1,2(0-2,3)\end{array}$ & 0,83 \\
\hline \multicolumn{7}{|l|}{ Sexo } \\
\hline $\begin{array}{l}\text { Masculino } \\
\text { Feminino }\end{array}$ & $\begin{array}{l}2,2(0-7,1) \\
2,5(0-8,4)\end{array}$ & 0,77 & $\begin{array}{c}2,5(0-41,1) \\
2,1(0-6,4)\end{array}$ & 0,84 & $\begin{array}{l}0,8(0-3,3) \\
1,1(0-2,6)\end{array}$ & 0,76 \\
\hline \multicolumn{7}{|l|}{ Tipo Histológico } \\
\hline $\begin{array}{l}\text { Esclerose nodular } \\
\text { Outros }\end{array}$ & $\begin{array}{l}2,4(0-8,4) \\
2,0(0-6,6)\end{array}$ & 0,28 & $\begin{array}{c}2,1(0-7,6) \\
2,6(0-41,1)\end{array}$ & 0,92 & $\begin{array}{l}0,7(0-2,3) \\
1,1(0-3,3)\end{array}$ & 0,38 \\
\hline \multicolumn{7}{|l|}{ Estádio } \\
\hline $\begin{array}{l}\mathrm{I} / \mathrm{II} \\
\mathrm{III/IV}\end{array}$ & $\begin{array}{l}2,2(0-6,6) \\
2,4(0-8,4)\end{array}$ & 0,67 & $\begin{array}{l}1,9(0-23,3) \\
2,4(0-41,1)\end{array}$ & 0,42 & $\begin{array}{c}1,3(0-3,3) \\
0(0-1,7)\end{array}$ & 0,03 \\
\hline \multicolumn{7}{|l|}{ Sintomas B } \\
\hline $\begin{array}{l}\text { Presentes } \\
\text { Ausentes }\end{array}$ & $\begin{array}{l}2,8(0-8,4) \\
2,2(0-7,1)\end{array}$ & 0,74 & $\begin{array}{l}2,1(0-23,3) \\
2,1(0-41,1)\end{array}$ & 0,83 & $\begin{array}{c}0(0-1,7) \\
0,7(0-3,3)\end{array}$ & 0,63 \\
\hline \multicolumn{7}{|l|}{ Doença bulky } \\
\hline $\begin{array}{l}\text { Ausente } \\
\text { Prsente }\end{array}$ & $\begin{array}{l}2,4(0-8,4) \\
2,2(0-7,1)\end{array}$ & 0,86 & $\begin{array}{l}2,0(0-41,1) \\
2,3(0-23,3)\end{array}$ & 0,91 & $\begin{array}{l}0,7(0-2,3) \\
1,5(0-3,3)\end{array}$ & 0,19 \\
\hline \multicolumn{7}{|l|}{ Hemoglobina } \\
\hline $\begin{array}{l}\geq 10,5 \mathrm{~g} / \mathrm{dL} \\
<10,5 \mathrm{~g} / \mathrm{dL}\end{array}$ & $\begin{array}{l}2,5(0-8,4) \\
2,2(0-7,1)\end{array}$ & 0,87 & $\begin{array}{l}3,2(0-41,1) \\
2,0(0-38,3)\end{array}$ & 0,07 & $\begin{array}{l}1,0(0-1,5) \\
0,5(0-3,3)\end{array}$ & 0,58 \\
\hline \multicolumn{7}{|l|}{ Leucócitos } \\
\hline $\begin{array}{l}<15000 \mathrm{~mm}_{3}^{3} \\
>15000 \mathrm{~mm}^{3}\end{array}$ & $\begin{array}{l}2,4(0-8,4) \\
2,0(0-7,1)\end{array}$ & 0,95 & $\begin{array}{l}2,1(0-41,1) \\
2,7(0-18,7)\end{array}$ & 0,69 & $\begin{array}{l}1,0(0-3,3) \\
0,7(0-1,5)\end{array}$ & 1,00 \\
\hline $\begin{array}{l}\text { Linfócitos } \\
\quad>600 \mathrm{~mm}^{3} \\
\leq 600 \mathrm{~mm}^{3}\end{array}$ & $\begin{array}{l}2,0(0-8,4) \\
2,5(0-5,5)\end{array}$ & 0,65 & $\begin{array}{l}2,1(0-23,3) \\
6,2(0-41,1)\end{array}$ & 0,10 & $\begin{array}{l}1,1(0-3,3) \\
0,3(0-1,5)\end{array}$ & 0,24 \\
\hline $\begin{array}{l}\text { Albumina } \\
\qquad \begin{array}{l}\geq 4,0 \mathrm{~g} / \mathrm{dL} \\
<4,0 \mathrm{~g} / \mathrm{dL}\end{array}\end{array}$ & $\begin{array}{l}2,7(0-6,1) \\
2,2(0-8,4)\end{array}$ & 0,27 & $\begin{array}{l}2,0(0-18,7) \\
2,5(0-41,1)\end{array}$ & 0,56 & $\begin{array}{l}0,1(0-1,1) \\
1,2(0-3,3)\end{array}$ & 0,01 \\
\hline \multicolumn{7}{|l|}{ VHS } \\
\hline $\begin{array}{l}\text { Até } 50 \mathrm{~mm} / \mathrm{h} \\
\text { Acima } 50 \mathrm{~mm} / \mathrm{h}\end{array}$ & $\begin{array}{l}2,4(0-6,0) \\
2,1(0-8,4)\end{array}$ & 0,78 & $\begin{array}{l}2,2(0-38,3) \\
2,1(0-41,1)\end{array}$ & 0,35 & $\begin{array}{l}0,7(0-2,3) \\
1,0(0-3,3)\end{array}$ & 0,59 \\
\hline \multicolumn{7}{|l|}{ IPI } \\
\hline $\begin{array}{l}\text { Baixo Risco } \\
\text { Alto Risco }\end{array}$ & $\begin{array}{l}2,5(0-6,6) \\
2,0(0-8,4)\end{array}$ & 0,34 & $\begin{array}{l}1,9(0-23,3) \\
2,7(0-41,1)\end{array}$ & 0,16 & $\begin{array}{l}1,0(0-3,3) \\
0,7(0-1,7)\end{array}$ & 0,66 \\
\hline
\end{tabular}

VHS: velocidade de hemossedimentação; IPI: Índice Prognóstico Internacional

Ao compararmos o perfil linfocitário entre pacientes e grupo controle, detectou-se uma diminuição na mediana da porcentagem de linfócitos T CD3 $+C D 4+$ nos pacientes $(p=0,02)$. De acordo com a literatura, o LHC é caracterizado por um influxo de células T CD4+, com imunofenótipo da população Th2 no infiltrado reacional, elevando a razão CD4/CD8 para 4:1 a 6:1 no tecido envolvido. ${ }^{2}$ Portanto, o acúmulo de linfócitos T CD3+CD4+ no tecido acometido pode estar associado com a diminuição do número destas células em sangue periférico. É provável que sejam as citocinas produzidas pelas células malignas (H-RS) e/ou células reativas as responsáveis por esta quimiotaxia. Estudos mostram que infiltrados inflamatórios intensos se aglomeram ao redor de tumores secretando diferentes citocinas, e que a natureza do infiltrado varia de acordo com as citocinas produzidas.,
As prováveis alterações imunológicas que ocorrem no LHC ficaram evidenciadas no nosso estudo pela avaliação das concentrações séricas das citocinas Th1/Th2 utilizandose o kit CBA, que permitiu a detecção e a quantificação das citocinas solúveis e que pode ser realizado utilizando-se tanto o plasma como amostras de soro dos pacientes. A análise das citocinas mostrou um aumento das concentrações de TNF $(p<0,01)$, INF- $\gamma(p<0,01)$, IL-4 $(p=0,01)$, IL-5 $(p<0,01)$ e IL-10 ( $\mathrm{p}<0,01)$ nos pacientes quando comparada com o grupo controle. Porém, não se observou diferença nos níveis séricos da IL-2 entre pacientes e controles. De acordo com Poppema, ${ }^{2}$ linfócitos periféricos de pacientes com LHC, quando colocados em cultura com agentes mitogênicos, tal como a concavalina $\mathrm{A}$, apresentam baixo índice de proliferação e ausência de síntese de IL-2. Sabe-se que a ausência de sínte- 
Tabela 3. Correlação entre citocinas séricas Th-2 (IL-4, IL-5, IL-10) e variáveis prognósticas

\begin{tabular}{|c|c|c|c|c|c|c|}
\hline Variável Prognóstica & $\begin{array}{l}\mathrm{IL}-4 \mathrm{pg} / \mathrm{mL} \\
\text { mediana } \\
\text { (variação) }\end{array}$ & $\mathrm{p}$ & $\begin{array}{l}\mathrm{IL}-5 \mathrm{pg} / \mathrm{mL} \\
\text { (variação) }\end{array}$ & $p$ & $\begin{array}{l}\text { IL-10 pg/mL } \\
\text { (variação) }\end{array}$ & $p$ \\
\hline $\begin{array}{l}\text { Idade } \\
\qquad<45 \text { anos } \\
\quad \geq 45 \text { anos }\end{array}$ & $\begin{array}{l}1,8(0-31,9) \\
2,5(0-3,1)\end{array}$ & 0,64 & $\begin{array}{l}1,9(0-14,5) \\
2,0(0-2,9)\end{array}$ & 0,90 & $\begin{array}{c}7,1(0-239,3) \\
9,3(2,8-255,1)\end{array}$ & 0,37 \\
\hline $\begin{array}{l}\text { Sexo } \\
\text { Masculino } \\
\text { Feminino }\end{array}$ & $\begin{array}{c}2,0(0-3,3) \\
1,7(0-31,9)\end{array}$ & 0,98 & $\begin{array}{c}1,9(0-5,9) \\
1,8(0-14,5)\end{array}$ & 0,56 & $\begin{array}{l}7,1(2,1-255,1) \\
8,4(2,0-273,9)\end{array}$ & 0,96 \\
\hline $\begin{array}{l}\text { Tipo Histológico } \\
\text { Esclerose nodular } \\
\text { Outros }\end{array}$ & $\begin{array}{l}1,5(0-31,9) \\
2,5(0-3,1)\end{array}$ & 0,18 & $\begin{array}{c}1,9(0-14,5) \\
1,9(0-5,9)\end{array}$ & 0,26 & $\begin{array}{c}8,2(0-273,9) \\
9,3(2,5-255,1)\end{array}$ & 0,53 \\
\hline $\begin{array}{l}\text { Estádio } \\
\text { I/II } \\
\text { III/IV }\end{array}$ & $\begin{array}{l}2,2(0-3,0) \\
1,4(0-31,9)\end{array}$ & 0,62 & $\begin{array}{r}2,1(1,3-5,9) \\
1,9(0-14,5)\end{array}$ & 0,26 & $\begin{array}{c}3,8(2,0-19,5) \\
10,4(2,0-273,9)\end{array}$ & 0,01 \\
\hline $\begin{array}{c}\text { Sintomas B } \\
\text { Presentes } \\
\text { Ausentes }\end{array}$ & $\begin{array}{l}2,3(0-3,0) \\
1,8(0-31,9)\end{array}$ & 0,73 & $\begin{array}{l}1,8(0-14,5) \\
2,1(1,3-5,9)\end{array}$ & 0,43 & $\begin{array}{c}9,3(2,0-273,9) \\
3,3(2,1-18,0)\end{array}$ & 0,04 \\
\hline $\begin{array}{l}\text { Doença bulky } \\
\text { Ausente } \\
\text { Prsente }\end{array}$ & $\begin{array}{c}2,8(0-31,9) \\
1,4(0-2,9)\end{array}$ & 0,13 & $\begin{array}{c}2,0(1,3-14,5) \\
1,9(0-5,9)\end{array}$ & 0,46 & $\begin{array}{l}5,2(2,1-273,9) \\
8,9(2,0-101,2)\end{array}$ & 0,63 \\
\hline $\begin{array}{l}\text { Hemoglobina } \\
\geq 10,5 \mathrm{~g} / \mathrm{dL} \\
<10,5 \mathrm{~g} / \mathrm{dL}\end{array}$ & $\begin{array}{l}2,0(0-3,0) \\
1,4(0-31,9)\end{array}$ & 0,97 & $\begin{array}{l}2,0(0-5,9) \\
1,8(0-14,5)\end{array}$ & 0,23 & $\begin{array}{c}5,4(2,0-102,5) \\
17,8(2,6-273,9)\end{array}$ & 0,01 \\
\hline $\begin{array}{l}\text { Leucócitos } \\
\qquad 15000 \mathrm{~mm}^{3} \\
\quad \geq 15000 \mathrm{~mm}^{3}\end{array}$ & $\begin{array}{c}1,9(0-31,9) \\
1,8(0-3,0)\end{array}$ & 0,84 & $\begin{array}{l}1,9(0-14,5) \\
2,2(0-3,4)\end{array}$ & 0,37 & $\begin{array}{l}6,1(2,0-273,9) \\
11,9(2,7-20,5)\end{array}$ & 0,42 \\
\hline $\begin{array}{l}\text { Linfócitos } \\
>600 \mathrm{~mm}^{3} \\
\quad \leq 600 \mathrm{~mm}^{3}\end{array}$ & $\begin{array}{c}1,5(0-3,0) \\
3,0(0-31,9)\end{array}$ & 0,02 & $\begin{array}{c}1,9(0-5,9) \\
2,9(0-14,5)\end{array}$ & 0,19 & $\begin{array}{c}7,1(2,0-101,2) \\
102,5(5,5-273,9)\end{array}$ & 0,01 \\
\hline $\begin{array}{l}\text { Albumina } \\
\qquad 4,0 \mathrm{~g} / \mathrm{dL} \\
<4,0 \mathrm{~g} / \mathrm{dL}\end{array}$ & $\begin{array}{l}2,5(0-3,0) \\
1,8(0-31,9)\end{array}$ & 0,69 & $\begin{array}{c}1,9(0-5,9) \\
1,9(0-14,5)\end{array}$ & 0,69 & $\begin{array}{c}2,7(0-101,2) \\
8,9(2,1-273,9)\end{array}$ & 0,07 \\
\hline $\begin{array}{l}\text { VHS } \\
\text { Até } 50 \mathrm{~mm} / \mathrm{h} \\
\text { Acima } 50 \mathrm{~mm} / \mathrm{h}\end{array}$ & $\begin{array}{c}1,4(0-3,0) \\
2,0(0-31,9)\end{array}$ & 0,47 & $\begin{array}{c}1,9(0-5,9) \\
1,9(0-14,5)\end{array}$ & 0,94 & $\begin{array}{l}4,4(2,0-102,5) \\
9,3(2,6-273,9)\end{array}$ & 0,09 \\
\hline $\begin{array}{l}\text { IPI } \\
\text { Baixo Risco } \\
\text { Alto Risco }\end{array}$ & $\begin{array}{c}1,9(0-3,0) \\
1,9(0-31,9)\end{array}$ & 0,78 & $\begin{array}{c}1,9(0-5,9) \\
1,8(0-14,5)\end{array}$ & 0,69 & $\begin{array}{c}3,8(2,0-101,2) \\
11,0(2,6-273,9)\end{array}$ & 0,01 \\
\hline
\end{tabular}

VHS: velocidade de hemossedimentação; IPI: Índice Prognóstico Internacional

se de IL-2 é uma característica de células anérgicas, e que esta citocina tem um papel chave na imunidade adaptativa Th1, pelo estímulo da proliferação de linfócitos CD4+ e da atividade antitumoral e citolítica das células NK e dos linfócitos T CD8 citotóxicos. ${ }^{6,8}$ Portanto, é provável que exista algum mecanismo no LHC que iniba a produção de IL-2, contribuindo com a anergia periférica descrita na literatura e evasão das células malignas H-RS às respostas imunes do hospedeiro.

Ao correlacionarmos as concentrações séricas das citocinas Th1/Th2 com as variáveis clínico-laboratoriais dos pacientes com LHC, observou-se que os níveis séricos aumentados da citocina IL-10 (Th2) estão correlacionados com as variáveis clínicas que implicam em pior prognóstico: estádios III/IV $(p=0,01)$, presença de sintomas $B(p=0,04)$, hemoglobina $<10,5 \mathrm{~g} / \mathrm{dL}(\mathrm{p}=0,01)$, linfócitos $\leq 600 \mathrm{~mm}^{3}$ $(p=0,01)$ e pacientes com IPI de alto risco $(p=0,01)$. Em anos recentes, a citocina IL-10 tem sido bastante estudada no LHC e vários autores identificaram níveis elevados desta citocina em uma proporção de pacientes. Esses autores sugerem que a IL-10 sérica poderia ser considerada um fator prognóstico independente das variáveis clínicolaboratoriais clássicas, consideradas pelo IPI, e que a esta citocina poderia auxiliar na identificação precoce de pacientes que necessitariam de tratamento mais agressivo ao diagnóstico. ${ }^{5,9-17}$

Sabe-se que a IL-10 é produzida por linfócitos Th2 e tem função inibitória sobre a produção de INF- $\gamma$ e IL-2, regulando negativamente a imunidade celular Th1., ${ }^{6,8}$ Portanto, de acordo com os nossos resultados e os dados da literatura, a IL-10 sérica elevada, no grupo de pacientes com variáveis que implicam pior prognóstico, poderia estar regulando ne- 
gativamente uma resposta imune Th1 ou citotóxica, contribuindo assim com a progressão da doença. Corroborando esses dados, também demonstramos que a IL-4 sérica mostrou-se elevada no grupo de pacientes com linfopenia $(\mathrm{p}=0,02)$, o que sugere uma associação entre citocinas Th2 e variáveis de pior prognóstico na doença.

Quando a citocina IL-2 foi correlacionada com as variáveis clínicas nos pacientes, foram observados valores séricos elevados nos estádios precoces I/II quando comparada aos estádios III/IV ( $\mathrm{p}=0,03)$, sugerindo que esta citocina diminui com a progressão da doença. Portanto, a citocina IL10 (Th2) poderia ser a responsável pela regulação negativa da citocina IL-2 (Th1), contribuindo com a polarização de uma resposta imune com perfil Th2, pouco efetiva em neoplasias, resultando na disseminação da doença. ${ }^{2,6}$

O CBA, que utiliza a sensibilidade de detecção da fluorescência amplificada por citometria de fluxo, mostrou ser uma técnica factível na detecção das citocinas séricas, com vantagens quando comparado com o procedimento por ELISA (imunoabsorção por ligação enzimática).

Os resultados apresentados neste estudo necessitam de validações adicionais para fornecer um perfil imune sistêmico e também de comparações, por esta metodologia, após tratamento dos pacientes. Além disso, um estudo simultâneo da expressão das citocinas no tecido envolvido e sua correspondente avaliação sérica proporcionaria uma maior compreensão da função e significado destas moléculas na fisiopatologia do LHC considerando suas características clínicas, histopatológicas e imunológicas.

\footnotetext{
Abstract

Classical Hodgkin lymphoma (CHL) is a malignancy with an abnormal or unbalanced secretion/production of cytokines, which might support the growth of H-RS cells, their surrounding reactive bystander cells and may be responsible for the typical clinical and histopathologic features of CHL: systemic B symptoms, an apparent defect in cell-mediated immune response, tumor fibrosis and eosinophilic infiltrate. Serum concentrations of IL-2, IL-4, IL5, IL-10, TNF and IFN- $\gamma($ Th1/Th2) were measured in 45 patients at diagnosis of classical Hodgkin lymphoma and in 34 healthy controls by cytometric beads array $(C B A)$. Levels of TNF $(p<0.01)$, $I N F-\gamma(p<0.01), I L-4(p=0.01), I L-5(p<0.01)$ e IL-10 $(p<0.01)$ were significantly higher in patients compared to the control group. No difference was observed for IL-2 between the two groups. On correlating Th1/Th2 cytokine concentrations with clinical risk factors, elevated IL-10 (Th2) levels are associated with variables that suggest worse prognoses including III/IV stage ( $p=0.01$ ), $B$ symptoms $(p=0.04)$, hemoglobin $<10.5 \mathrm{~g} / \mathrm{dL}(p=0.01)$, lymphocytes $\leq 600 / \mathrm{mm}^{3}(p=0.01)$ and according to the seven-factored international prognostic score (IPI), a subset of patients with a particularly high risk of failure $(p=0.01)$. Furthermore, the serum levels of IL-2 (Th1) were significantly higher in a group of I/II stage patients compared to III/IV patients $(p=0.03)$ which implies that, the levels of IL-2 might decrease with disease progression.
}

The elevated IL-10 levels in a subset of patients with poor clinical risk factors might down regulate a Th1 immune response by inhibiting IL-2 production causing survival disadvantage by suppression of the cytotoxic immune response against the tumor. This suggests an association between progression of CHL and higher levels of the IL-10 cytokine. This study showed that measurement of serum cytokines using the CBA methodology is highly reproducible, and that changes in concentrations seem to be involved in the biology of this diseas. Rev. Bras. Hematol. Hemoter. 2009;31(4):260-266.

Key words: Classical Hodgkin lymphoma; cytokines; flow cytometry; CBA; Th1 cells; Th2 cells.

\section{Referências Bibliográficas}

1. Stein H, Delsol G, Pileri S. Hodgkin Lymphoma. In: Jaffe ES, Harris NL, Stein H, Vardiman JW, eds. World Health Orghanization Classification of Tumours. Pathology and Genetics of Tumours on the Haematopoietic and Lymphoid Tissues. Lyon, France: IARC Press. 2001:237-354

2. Poppema S. Immunology of Hodgkin's disease. Baillieres Clin Haematol. 1996;9(3):447-57.

3. Küppers R. Molecular biology of Hodgkin's lymphoma. Adv Cancer Res. 2002;84:277-312.

4. Skinnider BF, Mak TW. The role of cytokines in classical Hodgkin lymphoma. Blood. 2002;99(12):4283-97.

5. Casasnovas RO, Mounier N, Brice P, Divine M, Morschhauser F, Gabarre J. Plasma cytokine and soluble receptor signature predicts outcome of patients with classical Hodgkin's lymphoma: a study from the Groupe d'Etude des Lymphomes de l'Adulte. J Clin Oncol. 2007;25(13):1732-40.

6. Powrie F, Coffman RL. Cytokine regulation of T-cell function: potential for therapeutic intervention. Immunol Today. 1993;14 (6):270-4.

7. Hasenclever D, Diehl V. A prognostic score for advanced Hodgkin's disease. International Prognostic Factors Project on Advanced Hodgkin's Disease. N Engl J Med. 1998;339(21): 1506-14.

8. Abbas AK, Lichtman AH. Cellular and Molecular Immunology. Elsevier Editora. 2007. 5a Edição: 307-326.

9. Sarris AH, Kliche KO, Pethambaram P, Preti A, Tucker S, Jackow $\mathrm{C}$, et al. Interleukin-10 levels are often elevated in serum of adults with Hodgkin's disease and are associated with inferior failure-free survival. Ann Oncol. 1999;10(4):433-40.

10. Bohlen H, Kessler M, Sextro M, Diehl V, Tesch H. Poor clinical outcome of patients with Hodgkin's disease and elevated interleukin10 serum levels. Clinical significance of interleukin-10 serum levels for Hodgkin's disease. Ann Hematol. 2000;79(3):110-3.

11. Dukers DF, Jaspars LH, Vos W, Oudejans JJ, Hayes D, Cillessen S, et al. Quantitative immunohistochemical analysis of cytokine profiles in Epstein-Barr virus-positive and -negative cases of Hodgkin's disease. J Pathol. 2000;190(2):143-9.

12. Rassidakis G, Medeiros LJ, Nadali G, Viviani S, Bonfante V, Vassilakopoulos T, et al. Expression of interleukin-10 (IL-10) in Hodgkin's disease (HD): pathologic and clinical associations. Blood. 2001;98:2511.

13. Vassilakopoulos TP, Nadali G, Angelopoulou MK, Siakantaris MP, Dimopoulou MN, Kontopidou FN, et al. Serum interleukin10 levels are an independent prognostic factor for patients with Hodgkin's lymphoma. Haematologica. 2001;86(3):274-81. 
14. Herling M, Rassidakis GZ, Medeiros LJ, Vassilakopoulos TP, Kliche $\mathrm{KO}$, Nadali G, et al. Expression of Epstein-Barr virus latent membrane protein-1 in Hodgkin and Reed-Sternberg cells of classical Hodgkin's lymphoma: associations with presenting features, serum interleukin 10 levels, and clinical outcome. Clin Cancer Res. 2003;9(6):2114-20.

15. Jutel M, Akdis M, Budak F, Aebischer-Casaulta C, Wrzyszcz M, Blaser K. IL-10 and TGF-beta cooperate in the regulatory T cell response to mucosal allergens in normal immunity and specific immunotherapy. Eur J Immunol. 2003;33(5):1205-14.

16. Visco C, Vassilakopoulos TP, Kliche KO, Nadali G, Viviani S, Bonfante $\mathrm{V}$, et al. Elevated serum levels of IL-10 are associated with inferior progression-free survival in patients with Hodgkin's disease treated with radiotherapy. Leuk Lymphoma. 2004;45 (10):2085-92.

17. Re D, Thomas RK, Behringer K, Diehl V. From Hodgkin disease to Hodgkin lymphoma: biologic insights and therapeutic potential. Blood. 2005;105(12):4553-60.

Suporte Financeiro: Fundação Maria Cecilia Souto Vidigal e HC-FMUSP

Avaliação: Editor e dois revisores externos

Recebido: 18/11/2008

Aceito após modificações: 07/02/2009 